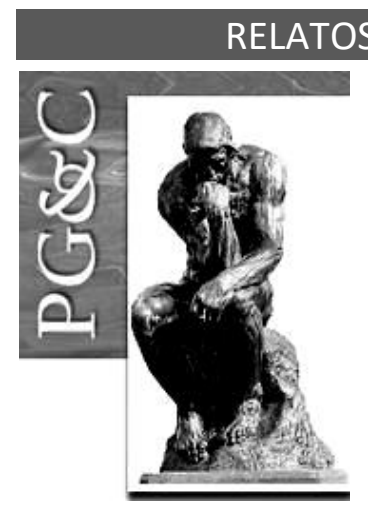

\title{
RAMOS DE PESQUISA E REDES DE COLABORAÇÃO NA PRODUÇÃO CIENTÍFICA DO PROGRAMA DE PÓS- GRADUAÇÃO EM DIREITO DA UNIVERSIDADE FEDERAL DA BAHIA
}

\author{
Natanael Vitor Sobral \\ Doutor em Ciência da Informação pela Universidade Federal da Bahia, Brasil. \\ Professor da Universidade Federal da Bahia, Brasil. \\ E-mail: natanvsobral@gmail.com \\ Raimundo Nonato Macedo dos Santos \\ Doutor em Information Stratégique Et Critique Veille Technol pela Université \\ Paul Cézanne Aix Marseille III, França. Professor da Universidade Federal de \\ Pernambuco, Brasil. \\ E-mail: rnmacedo@uol.com.br \\ Susane Santos Barros \\ Doutoranda em Educação e Contemporaneidade pela Universidade do Estado \\ da Bahia, Brasil. Professora da Universidade Federal da Bahia, Brasil. \\ E-mail: susanesb@gmail.com \\ Brenda Bárbara Costa Ribeiro \\ Graduanda em Direito pela Universidade Federal da Bahia, Brasil. \\ E-mail: brendabarbarar@gmail.com \\ Jussara de Souza Farias \\ Graduanda em Biblioteconomia e Documentação pela Universidade Federal \\ da Bahia, Brasil. \\ E-mail: jussaradesouza6@gmail.com
}

\begin{abstract}
Resumo
A pesquisa em relato tem por objetivo descrever os ramos de pesquisa e as redes de colaboração na produção científica do Programa de Pós-Graduação em Direito da Universidade Federal da Bahia (PPGD/UFBA), no ano 2018. Os fundamentos metodológicos estão baseados em indicadores cientométricos e na Análise de Domínio. Os procedimentos metodológicos baseiam-se no seguinte fluxo: 1) extração de dados da Plataforma Lattes do Conselho Nacional de Desenvolvimento Científico e Tecnológico por meio do software ScriptLattes; e 2) sistematização e representação gráfica com apoio das ferramentas The Vantage Point, Microsoft Excel, UCINET, NetDraw e Wordle. Os resultados revelam o enfoque da produção em Direito Civil e Constitucional e apontam para a alta colaboração científica entre Teixeira, L. F. e Pamplona Filho, R. Além disto, identificou-se a proeminência de três revistas científicas entre os veículos utilizados pelo PPGD/UFBA e uma concentração de publicações em periódicos nacionais e internacionais de importante qualidade, ressaltando-se o estrato Qualis B1. Ao mesmo tempo, uma quantidade significativa de artigos foi publicada em periódicos sem Qualis, provavelmente, revistas novas ou estratificadas em outras áreas. Por fim, espera-se que o presente estudo possa fundamentar novos estudos métricos no campo jurídico, contribuindo para a avaliação da comunicação científica na área, em especial, com a utilização dos aportes teóricos e metodológicos da Ciência da Informação.
\end{abstract}

Palavras-chave: Direito. Produção Científica. Redes de Colaboração. Cientometria. Programa de PósGraduação em Direito - Universidade Federal da Bahia.

Perspectivas em Gestão \& Conhecimento, João Pessoa, v. 11, n. 1, p. 99-117, jan./abr. 2021. DOI: http://dx.doi.org/10.22478/ufpb.2236-417X.2021v11n1.54759

http://periodicos.ufpb.br/ojs2/index.php/pgc. ISSN: 2236-417X. Publicação sob Licença (cc) EY-NC-ND 


\title{
RESEARCH BRANCHES AND COLLABORATION NETWORKS IN THE SCIENTIFIC PRODUCTION OF THE LAW GRADUATE PROGRAM AT THE FEDERAL UNIVERSITY OF BAHIA
}

\begin{abstract}
The research in report aims to describe the branches of research and the collaboration networks in the scientific production of the Graduate Program in Law at the Federal University of Bahia (PPGD/UFBA), in the year 2018. The methodological foundations are based on scientometrics indicators and domain analysis. The methodological procedures are based on the following flow: 1) data extraction from the Lattes Platform of the National Council for Scientific and Technological Development through the Scriptlattes software; and 2) systematization and graphic representation with the support of The Vantage Point, Microsoft Excel, UCINET, NetDraw and Wordle tools. The results reveal the focus of production in Civil and Constitutional Law and point to the high scientific collaboration between Teixeira, LF and Pamplona Filho, R. In addition, the prominence of three journals was identified among the vehicles used by PPGD/UFBA and a concentration of publications in national and international journals of important quality, with emphasis on the Qualis B1 stratum. At the same time, a significant number of articles were published in journals without Qualis, probably new or stratified journals in other areas. Finally, it is hoped that the present study can support new metric studies in the legal field, contributing to the evaluation of scientific communication in the area, in particular, with the use of theoretical and methodological contributions from Information Science.
\end{abstract}

Keywords: Law Science. Scientific production. Collaboration Networks. Scientometrics. Graduate Program in Law - Federal University of Bahia.

\section{INTRODUÇÃO}

A Ciência da Informação $(\mathrm{Cl})$ está relacionada a diversas disciplinas e áreas científicas, visto que realiza interações profundamente interdisciplinaridades com outros territórios do conhecimento. Na visão de Martins (2012), uma das características da $\mathrm{Cl}$ é auxiliar outros campos. Todavia, a presença desse perfil não necessariamente retira seu estatuto próprio de área do conhecimento científico, pelo contrário, o amplia na medida em que encontra utilidade em outros espaços de aplicação cientificamente instituídos e complementa outros saberes, trazendo maior sentido para os fenômenos que envolvem o objeto "informação", dependentes, por natureza, de olhares multirreferenciais para sua compreensão.

Entende-se que o propósito da $\mathrm{Cl}$ é produzir conhecimentos e refletir sobre a informação e fenômenos a ela relacionados na sociedade, preocupando-se com seus impactos econômicos, sociais, educacionais e culturais (FERREIRA, 1999).

Dentre os campos que possuem relações históricas e interlocuções consolidadas com a $\mathrm{Cl}$ ao longo do tempo, um dos mais representativos é o Direito, e isto pode ser observado na produção científica indexada na Base de Dados Referencial de Artigos de Periódicos em Ciência da Informação (Brapci), a partir de vários estudos, como, por exemplo, Sobriño (1979), que discutiu questões relacionadas a bibliotecas no campo jurídico; o Grupo de Trabalho em Documentação Jurídica de Minas Gerais, que debateu a iniciativa de um catálogo coletivo de periódicos em Ciências Jurídicas (GTDJMG, 1977). Mais à frente, nos anos 1990, diante das novas configurações de mundo, o perfil da produção em $\mathrm{Cl}$ sobre o campo do Direito passou a enfatizar as questões de Direito autoral, conforme se observa nos estudos de Michel (1997), Antonio (1998) e Martins Filho (1998).

Após os anos 2000, com o avanço do advento tecnológico e o crescimento das demandas de transparência política, houve um aumento significativo das produções envolvendo os dois campos, em especial, nos temas voltados ao direito de acesso à

Perspectivas em Gestão \& Conhecimento, João Pessoa, v. 11, n. 1, p. 99-117, jan./abr. 2021. 
informação, motivado pela Lei de Acesso à Informação, como se vê nos estudos de Carli e Fachin (2017) e na manutenção do foco nas questões de direitos autorais, sobretudo, no âmbito da Internet (BRITTES; PEREIRA, 2007), estabelecendo, assim, a mudança de um paradigma bibliográfico para um sociopolítico, no que concerne às relações Direito-Informação na produção científica.

Considerando o avanço das ferramentas bibliométricas e a manutenção das relações mútuas entre os campos em questão, neste artigo, despertou-se o interesse de retomar o enfoque bibliométrico para a área do Direito, ao incorporar as possibilidades mais recentes dos estudos métricos da informação, fugindo da lógica tradicional de contagem de autores mais produtivos e citações. Dado o caráter experimental do artigo, escolheu-se um universo circunscrito, que são os pesquisadores do Programa de Pós-Graduação em Direito da Universidade Federal da Bahia (PPGD/UFBA). Esse conjunto de atores teve seus dados acadêmicos e científicos cadastrados no anuário estatístico de produção científica, acadêmica e tecnológica da UFBA, coletados a partir de um projeto de pesquisa desenvolvido em 2019.

Assim, o objetivo deste artigo é descrever os ramos de pesquisa e as redes de colaboração na produção científica do PPGD/UFBA no ano 2018. Como adendo, espera-se que a metodologia apresentada se revele promissora para fundamentar novos estudos métricos no campo jurídico, contribuindo para a avaliação da comunicação científica na área, especialmente, com a utilização dos aportes teóricos e metodológicos da $\mathrm{Cl}$.

\section{QUADRO TEÓRICO}

De acordo com Silva (2006), o Direito constitui um conjunto ordenado e sistemático de princípios e regras que tem por tarefa definir e sistematizar o ordenamento jurídico que o Estado impõe à sociedade e apontar soluções para os problemas ligados à sua interpretação, aplicação e fontes. Na visão de Albergaria (2008), o Direito pode ser entendido como um conjunto de regras obrigatórias a todos, impostas pelo Estado, que, em caso de não cumprimento, podem se tornar objeto de um processo e, ao final, gerar condenação e penalização. O Estado, para dar cumprimento à sanção, age coercitivamente, utilizando-se, se necessário, da força física.

Mascaro (2015) lembra que o objeto atualmente denominado "Direito", não existiu sempre na história. O Direito é um fenômeno vinculado à contemporaneidade das sociedades, principalmente, às subordinadas ao modo de produção capitalista, estando diretamente relacionado ao estabelecimento do conceito de propriedade. Nesse tipo de arranjo social, todas as relações entre as pessoas e os pactos políticos da sociedade se dão de acordo com uma manifestação que é jurídica. Essa ideia de pensamento coaduna com o que afirmava Hegel (2003), ao dizer que o Direito é fruto do contexto social, sendo assim, o reflexo do que somos como sociedade (MARTINS; ALMEIDA, 2012).

Tradicionalmente, o Direito é dividido em dois ramos, sendo eles, o Direito Público e o Direito Privado. De acordo com Ferraz Júnior (2003), essa dicotomia tem origem no Direito Romano, onde sua base é um trecho da obra de Ulpiano (Digesto, 1.1.1.2), que afirma: "Publicum jus est quod ad statum rei romanae spectat, privatum, quod ad singulorum utilitatem" - "O direito público diz respeito ao estado da coisa romana, à polis ou civitas, o privado à utilidade dos particulares".

Entretanto, na Classificação Decimal de Direito elaborada por Carvalho (2002), dividiram-se os ramos do Direito em quatro classes, adicionando-se ao Direito Público e ao Direito Privado, o Direito Canônico e Eclesiástico, e o Direito Romano.

Assim, buscando defini-los, Carvalho (2019) diz que o Direito Público tem por objeto principal a regulação dos interesses da sociedade como um todo, compondo-se de normas que visam disciplinar as relações jurídicas em que o Estado aparece como parte. Percebe-se a

Perspectivas em Gestão \& Conhecimento, João Pessoa, v. 11, n. 1, p. 99-117, jan./abr. 2021. 
desigualdade das relações jurídicas como uma das características básicas desse ramo do Direito, visto que o interesse público deve prevalecer sobre o interesse individual.

Ainda segundo Carvalho (2019), entende-se que o Direito Privado tem como propósito a regulação dos interesses dos particulares, tutelando as relações travadas entre as partes como forma de possibilitar o convívio das pessoas em sociedade. Está baseado, assim, na igualdade jurídica entre as pessoas envolvidas, uma vez que os interesses tutelados são privados, não podendo haver, em princípio, qualquer relação de subordinação ou desigualdade entre as partes.

O Direito Canônico é entendido como o sistema ou complexo de leis com que a Igreja regula a sua atividade social específica e a de seus membros (GIGANTE, 1954), sendo uma disciplina eminentemente jurídica, pois o eventual interesse da Teologia pelo campo não afeta a sua natureza (KLAUSNER, 2019). Já o Direito Romano é considerado como o conjunto dos princípios e das normas jurídicas que vigoraram em Roma e nos territórios dominados por ela desde a fundação da cidade, em 753 a. C., até a morte de Justiniano, imperador do Oriente, em 565 d. C. (AMARAL, 2003).

Conforme indica a Classificação Decimal de Direito, os ramos do Direito Público são: Direito Internacional Público, Direito Constitucional, Direito Administrativo, Direito Processual, Direito Penal, Direito Previdenciário (Seguridade Social), Direito Militar e Direito Aéreo (Código do Ar). O Direito Privado engloba: Direito Civil, Direito Comercial, Direito Internacional Privado, Direito do Consumidor e Direito do Trabalho. O Direito Canônico e Eclesiástico possui as subdivisões: Direito das coisas (Direitos reais), Direito Penal Canônico, Direito Processual Canônico, Direito Eclesiástico das Igrejas Cristãs não católicas e Direito Eclesiástico de Igrejas não cristãs. Por fim, o Direito Romano divide-se em: Direito das coisas (Direitos reais), Direito das obrigações, Direito de família e Direito das sucessões (CARVALHO, 2002).

Tal classificação, além de disciplinar o campo, mostra-se útil para a organização do conhecimento no Direito, principalmente, no quesito sistematização das produções bibliográficas elaboradas pelos pesquisadores que aderem, direta ou indiretamente, a algum ramo específico da área.

Ao profissional da informação com atuação na área jurídica, cabe conhecer e entender os principais conceitos e ramificações do domínio em que atua, tendo em vista, que o processo de construção de produtos e serviços de informação para outras áreas do conhecimento depende da compreensão das necessidades de um conjunto de usuários. Eles constituem um campo com demandas, culturas, ideologias, técnicas e princípios próprios, que precisam ser observados e respeitados para que as ações em informação tenham adesão e relevância, sendo percebidas pelo público-alvo.

Sobre isso, entende-se que existe um amplo conjunto de conhecimentos que um profissional/pesquisador especialista em informação precisa obter para trabalhar em domínios específicos, como é o caso do jurídico. Hjørland (2002) afirma que a produção de guias de leitura, classificações e tesauros, indexações e recuperação de informações especializadas, estudos de usuários, análises bibliométricas, pesquisas históricas, estudos de documentos e gênero, estudos epistemológicos e críticos, estudos terminológicos e de discurso, estudos de estruturas e instituições em comunicação científica, análise de domínio em cognição profissional e inteligência artificial são abordagens presentes no cotidiano do profissional/pesquisador da informação especialista em domínios circunscritos. E, assim, constituem-se como recursos fundamentais de organização da informação e do conhecimento a serem aplicados.

No contexto de um Programa de Pós-Graduação em Direito, constata-se que parte importante das demandas em informação estão explicitamente postas nas regras das instâncias avaliativas e de fomento, que criam arcabouços normativos com o intuito de regular e conceder auxílios e patrocínios para a sustentação do Programa, e um dos eixos de maior

Perspectivas em Gestão \& Conhecimento, João Pessoa, v. 11, n. 1, p. 99-117, jan./abr. 2021. 
peso é a produção científica. Por esse motivo, os instrumentos de medição da informação apoiados pelas ferramentas de organização da informação e do conhecimento são indispensáveis.

Aqui, entende-se a produção científica como o conhecimento crível, publicado e aceito socialmente pela comunidade científica. Desse modo, cumpre aos indicadores científicos apoiar as reflexões sobre as atividades desenvolvidas pelas instituições de ensino e pesquisa. Assim, neste artigo, faz-se isto concernente ao PPGD/UFBA, tendo como base os dados disponíveis na Plataforma Lattes do Conselho Nacional de Desenvolvimento Científico e Tecnológico (PL/CNPq).

\section{METODOLOGIA}

A metodologia empregada neste estudo engloba duas frentes principais. A primeira relaciona-se à cientometria, definida por Silva e Bianchi $(2001$, p. 1) como "[...] o estudo da mensuração e quantificação do progresso científico". É o estudo dos aspectos quantitativos da ciência como uma disciplina ou atividade econômica. A cientometria é um segmento da sociologia da ciência, sendo aplicada no desenvolvimento de políticas científicas. Envolve estudos quantitativos das atividades científicas, incluindo a publicação e, portanto, sobrepondo-se à bibliometria (TAGUE-SUTCLIFFE, 1992).

Os indicadores cientométricos são fundamentais para a construção de redes de colaboração, mapas temáticos, rankings de produtividade dos pesquisadores e contextualização dos comportamentos encontrados junto a outras áreas e estudos.

A segunda frente filia-se à Análise de Domínio (AD), que é uma teoria e uma abordagem para as áreas de $\mathrm{Cl}$ e Organização do Conhecimento. Neste contexto, abordam-se questões de sistemas e processos de organização do conhecimento a partir de uma perspectiva sociológica e epistemológica combinada, enfatizando a importância do conhecimento de assunto (HJØRLAND, 2017). A AD fortalece os estudos cientométricos na medida em que criam possibilidades de classificação do conhecimento, evitando a dispersão e atribuindo sentido a dados, que, a princípio, apenas expressam fatos brutos.

Visando atingir o objetivo proposto, realizou-se o fluxo de procedimentos apresentado a seguir.

a) Constituição do universo: $\mathrm{Na}$ Plataforma Sucupira da Coordenação de Aperfeiçoamento de Pessoal de Nível Superior (Capes), mapearam-se os pesquisadores lotados no PPGD/UFBA, no ano 2018. Com isso, verificou-se a existência de 39 docentes, sendo nove colaboradores e 30 permanentes.

b) Extração dos dados: Para a realização do levantamento dos dados dos pesquisadores optou-se pela PL/CNPq. Esta base de dados é um padrão nacional no registro das atividades acadêmicas dos pesquisadores do país. A ferramenta utilizada para extração dos dados foi o Scriptlattes (MENA-CHALCO; CÉSAR JUNIOR, 2009), sendo possível obter relatórios de produção bibliográfica. As variáveis consideradas para este estudo foram: pesquisadores do PPGD/UFBA autores de artigos científicos em 2018, seus coautores, revistas científicas em que publicaram, palavras-chave definidas a partir dos títulos dos artigos, Qualis Capes (2013-2016) e ramos do Direito. O processamento dos resultados foi realizado entre o segundo semestre de 2019 e o primeiro semestre de 2020.

c) Categorização dos artigos segundo os ramos do Direito: Apesar de existirem várias formas de classificação do conhecimento jurídico, optou-se pela Classificação Decimal de Direito, proposta por Carvalho (2002). Para a categorização adequada, adotou-se o seguinte conjunto de regras: 1) Exclusividade, significa que as categorias devem ser mutuamente excludentes, ou seja, sob nenhuma hipótese um artigo pode ser 
cadastrado em mais de uma classe temática (BARDIN, 2009; CARLOMAGNO; ROCHA, 2016; KRIPPENDORFF, 2004); 2) Método de inclusão e exclusão nas categorias, inspirando-se no processo de indexação no contexto da análise documentária, que compreende dois estágios: o analítico, em que é realizada a compreensão do texto como um todo, e o estágio de tradução, que consiste na representação de conceitos por termos de um vocabulário controlado (FUJITA, 2003). Neste caso, julgou-se o vocabulário de controle terminológico não como um thesaurus, mas, sim, as categorias propostas pela Classificação de Carvalho (2002). A fase de compreensão do todo se viabilizou pelo corpus reduzido, 99 artigos completos publicados em periódicos, e pela presença do título e resumo disponíveis na web, facilitadores do acesso cognitivo ao aboutness, ou seja, à temática dos documentos (PEDRINI, 2007).

d) Sistematização dos indicadores: Os dados foram padronizados e corrigidos na ferramenta The VantagePoint ${ }^{\circledR}$, visando minimizar e eliminar as incongruências da $\mathrm{PL} / \mathrm{CNPq}$. Em seguida, utilizaram-se as ferramentas Microsoft Excel ${ }^{\circledR}$, com o propósito de tabulação, e os softwares UCINET ${ }^{\circledR}$ \& NetDraw $^{\circledR}$ (BORGATTI; EVERETT; FREEMAN, 2002) para a elaboração dos grafos, seguindo os princípios metodológicos estabelecidos pelo domínio da Análise de Redes Sociais (ARS). Outra representação explorada foi a nuvem de palavras. Para sua construção, utilizaram-se técnicas de processamento de linguagem natural, que particionaram automaticamente os títulos dos artigos em termos simples, e quando fazia sentido, mantinham-se as expressões compostas. Visando evitar a dispersão, uniram-se os termos singulares e plurais, mitigando problemas de sinonímia típicos de estudos bibliométricos. A visualização foi criada na ferramenta wordle $^{\circledR}$.

\section{RESULTADOS E DISCUSSÃO}

Os resultados estão apresentados em duas subseções. A primeira enfatiza os autores do PPGD/UFBA, seus coautores e os ramos do Direito, pautando-se nas seguintes análises: a) Rede de colaboração do PPGD/UFBA e seus coautores nas publicações de artigos; b) Distribuição percentual dos ramos do Direito nas publicações de artigos do PPGD/UFBA; c) Nuvem de palavras com base nos títulos dos artigos do PPGD/UFBA; d) Pesquisadores do PPGD/UFBA e seus coautores versus ramos do Direito nas publicações de artigos. A segunda enfoca as publicações do PPGD/UFBA em periódicos e suas variáveis, expondo as seguintes pautas: a) Periódicos mais representativos nas publicações do PPGD/UFBA; b) Qualis Capes das publicações do PPGD/UFBA na área de avaliação "Direito"; c) Qualis Capes dos periódicos versus ramos do Direito nas publicações de artigos do PPGD/UFBA.

A princípio, referente ao ano 2018, identificaram-se: 99 artigos completos publicados em periódicos, 56 livros publicados/organizados, 112 capítulos de livros publicados, 63 textos em jornais de notícias/revistas, 19 trabalhos completos publicados em anais de congressos, um resumo expandido publicado em anais de congressos, um resumo publicado em anais de congressos e 117 apresentações de trabalho em eventos.

Em relação às atividades acadêmicas concluídas, mapearam-se: uma supervisão de pós-doutorado, quatro orientações de tese de doutorado, 54 de dissertação de mestrado, 132 de trabalho de conclusão de curso de graduação e 14 de iniciação científica. No mais, são 14 projetos de pesquisa registrados, 231 participações em eventos e 11 organizações de eventos.

\subsection{Autores do PPGD/UFBA, seus coautores e ramos do Direito}

Inicialmente, mapearam-se as inter-relações entre os pesquisadores do PPGD/UFBA, incluindo os coautores presentes em suas produções. Este tipo de análise corrobora com a

Perspectivas em Gestão \& Conhecimento, João Pessoa, v. 11, n. 1, p. 99-117, jan./abr. 2021. 
visão de Silva (2014), que enxerga neste enfoque de estudo a possibilidade de observar as vias de cooperação, participação e auxílio entre os pesquisadores, em conformidade com a essência etimológica da palavra "colaboração". O retrato desta dinâmica social pode ser observado na Figura 1, onde os nós, de cor verde, são os docentes do PPGD/UFBA e os de cor azul são seus colaboradores na produção de artigos. A espessura dos vínculos é proporcional à quantidade de coautorias identificadas.

Figura 1 - Rede de Colaboração do PPGD/UFBA e seus coautores nas publicações de artigos

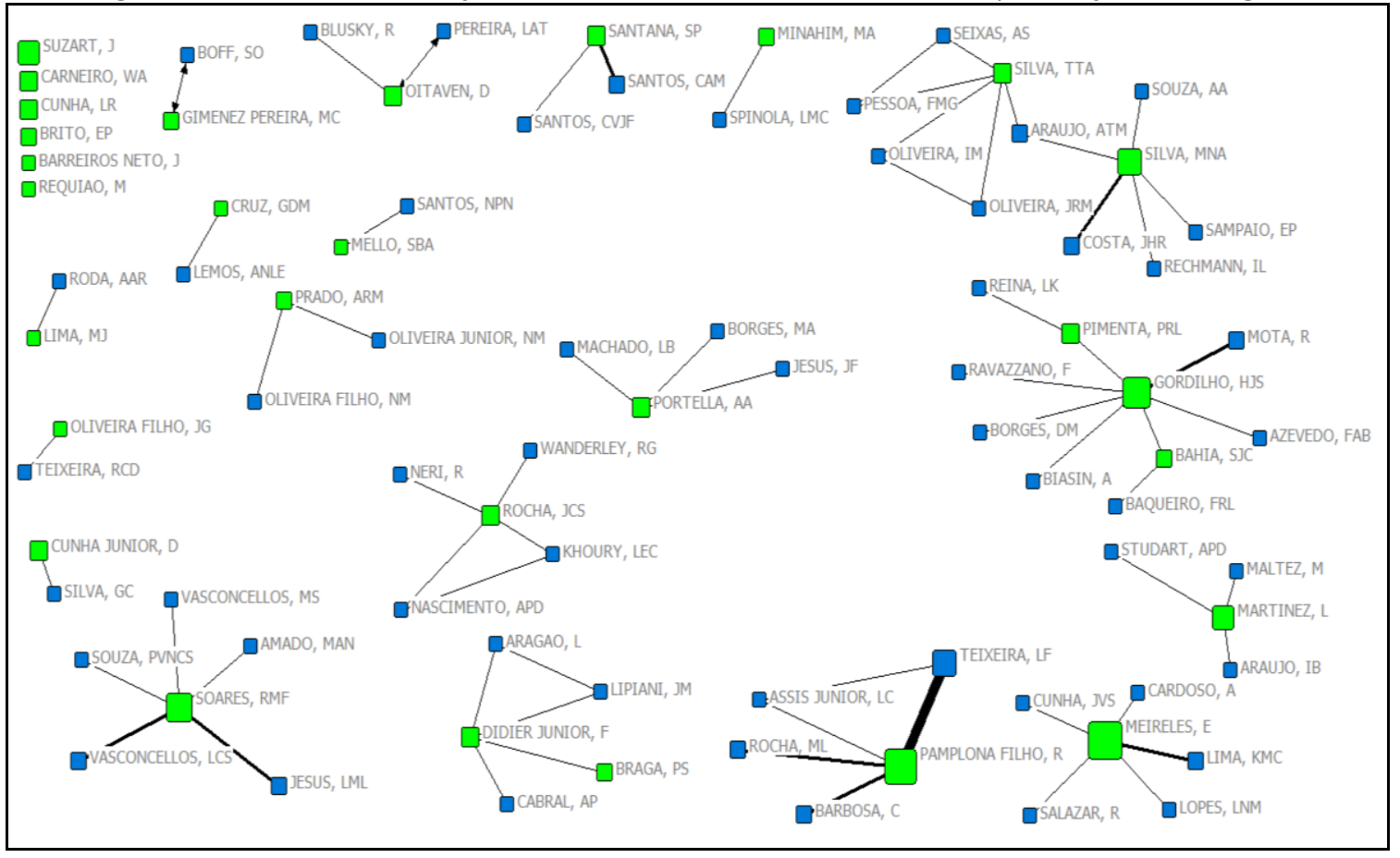

Fonte: Dados da pesquisa (2020)

Sobre esta rede de colaboração, identificou-se que os vínculos mais estreitos são formados pelos pesquisadores: Teixeira, LF \& Pamplona Filho, $R$ (5). $O$ primeiro, Leandro Fernandez Teixeira, segundo informações da PL/CNPq, é Juiz do Trabalho Substituto no Tribunal Regional do Trabalho da 6a Região, tendo sido orientado na graduação, mestrado e agora no doutorado na Faculdade de Direito da UFBA pelo Professor Doutor do PPGD/UFBA Rodolfo Mário Veiga Pamplona Filho, Juiz do Trabalho da 32a Vara do Trabalho de Salvador, na Bahia, conforme informações de seu currículo Lattes. Assim, ciente dessa trajetória comum, constata-se a origem da alta produtividade colaborativa. Observa-se que a colaboração entre os autores mencionados se dá, majoritariamente, sobre o tema Direito do Trabalho, onde são abordados assuntos como Direito Processual do Trabalho, Teletrabalho e Reforma Trabalhista.

Em seguida, com dois artigos em coautoria figuram os seguintes pares de pesquisadores: Lima, KMC \& Meireles, E; Gordilho, HJS \& Mota, R; Costa, JHR \& Silva, MNA; Santana, SP \& Santos, CAM; Soares, RMF \& Vasconcelos, LCS; Soares, RMF \& Jesus, LML; Pamplona Filho, $R$ \& Rocha, ML; Pamplona Filho, $R$ \& Barbosa, $C$.

Uma observação perceptível ao realizar-se o tratamento dos dados, foi o predomínio de pesquisadores brasileiros na rede de coautores. Tal característica nos cursos de Direito é verificada por Capparelli e Giacomolli (2017), quando afirmam que a pesquisa nas Ciências Jurídicas, frequentemente, possui um foco local, enquanto a pesquisa nas ciências duras, é orientada em nível internacional e os pesquisadores pertencentes a esse grupo são fortemente inclinados à internacionalização, considerado o valor e o impacto universal dos temas e 
objetos de pesquisa. Inclusive, o grau de cooperação internacional é distinto: enquanto é indispensável ter um alto grau de cooperação internacional nas áreas duras, registra-se um nível muito mais baixo de cooperação internacional no campo jurídico (CAPPARELLI; GIACOMOLLI, 2017).

Ao detectarem-se expressivas quantidades de vínculos na rede, tem-se a impressão da existência de densidade e alto grau de interconexão entre os nós. Todavia, percebe-se que os indivíduos em verde, ou seja, os pesquisadores do PPGD/UFBA, estabelecem suas próprias redes de colaboração, em geral, com orientandos, não havendo grande número de produções entre os pares. Este comportamento remete aos achados de Fragale Filho e Veronese (2004), quando apontam como característica do Direito, a atuação de pesquisadores isolados, o que gera, no imaginário da sociedade, a ideia do doutrinador intelectual debruçado sobre os livros, a construir opinião abalizada sobre os fatos e a norma. Tal paradigma vem sendo descontruído ao longo dos anos em vários campos científicos a partir do avanço da colaboração e das redes interdisciplinares, todavia, no Direito, ainda se mostra presente de maneira significativa.

No Gráfico 1, discutem-se os ramos do Direito mais expressivos na produção do PPGD/UFBA. Para isto, apresenta-se o gráfico circular contendo as proporções das categorias analisadas.

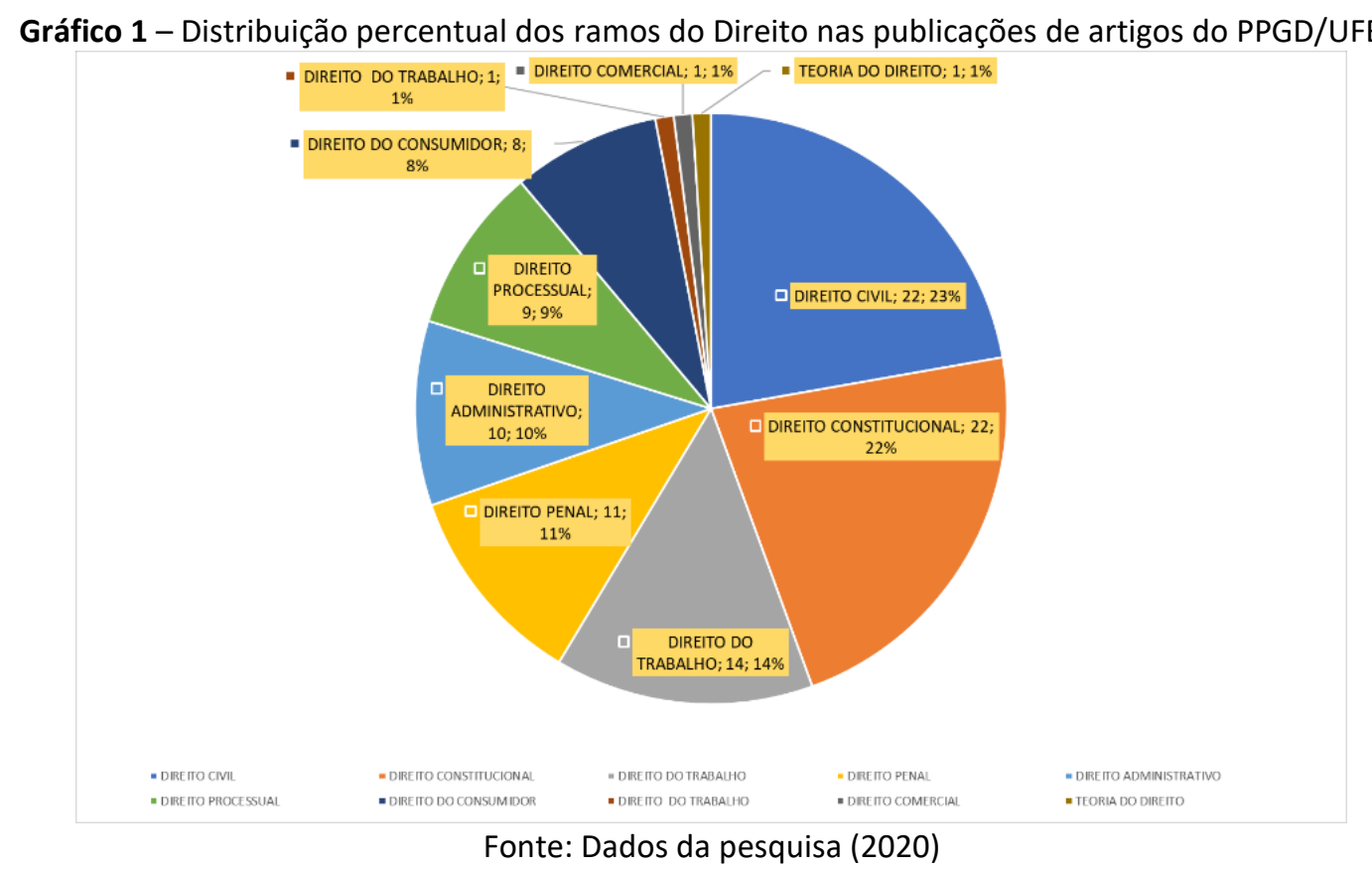

Em relação aos ramos do Direito, obteve-se o seguinte panorama de quantidade de artigos: Direito Constitucional (22), Direito Civil (22), Direito do Trabalho (14), Direito Penal (11), Direito Administrativo (10), Direito Processual (9), Direito do Consumidor (8), Direito do Trabalho (1), Direito Comercial (1) e Teoria do Direito (1). Observa-se que a maior parte de artigos publicados está relacionada ao Direito Constitucional e ao Direito Civil, ambos com 22 registros. Esses números refletem a área de concentração do PPGD/UFBA, já que o programa de Mestrado tem como foco Direitos Fundamentais e Acesso à Justiça e o programa de Doutorado aborda Jurisdição Constitucional e novos direitos, áreas intrínsecas ao Direito Constitucional e que também se relacionam com o Direito Civil. A este panorama de concentração temática, cabe expressivo destaque, pois, o saber jurídico demanda contínua atualização e suas disciplinas devem estar imbricadas às perspectivas da sociedade, sendo 
sensíveis ao que nela ocorre (FACHIN, 2013). Neste caso, as linhas temáticas trazem luz ao atual debate público que se ergue na sociedade sobre a Constituição Federal.

Quanto ao Direito Constitucional, sua predominância torna-se visível ao observar-se a nuvem de palavras criadas a partir do processamento de linguagem natural dos títulos dos artigos de periódicos (Figura 2). Nela, observa-se o destaque dos Direitos Fundamentais, em consonância com a área de concentração do mestrado do PPGD/UFBA, e Constituição, que se alinha profundamente à área de concentração do doutorado. Tais percepções demonstram o direcionamento adequado do Programa aos compromissos temáticos estabelecidos junto à universidade, às instâncias reguladoras, e sobretudo, à sociedade, principalmente, no que concerne à pesquisa em assuntos ligados ao Direito Constitucional.

Figura 2 - Nuvem de palavras com base nos títulos dos artigos do PPGD/UFBA

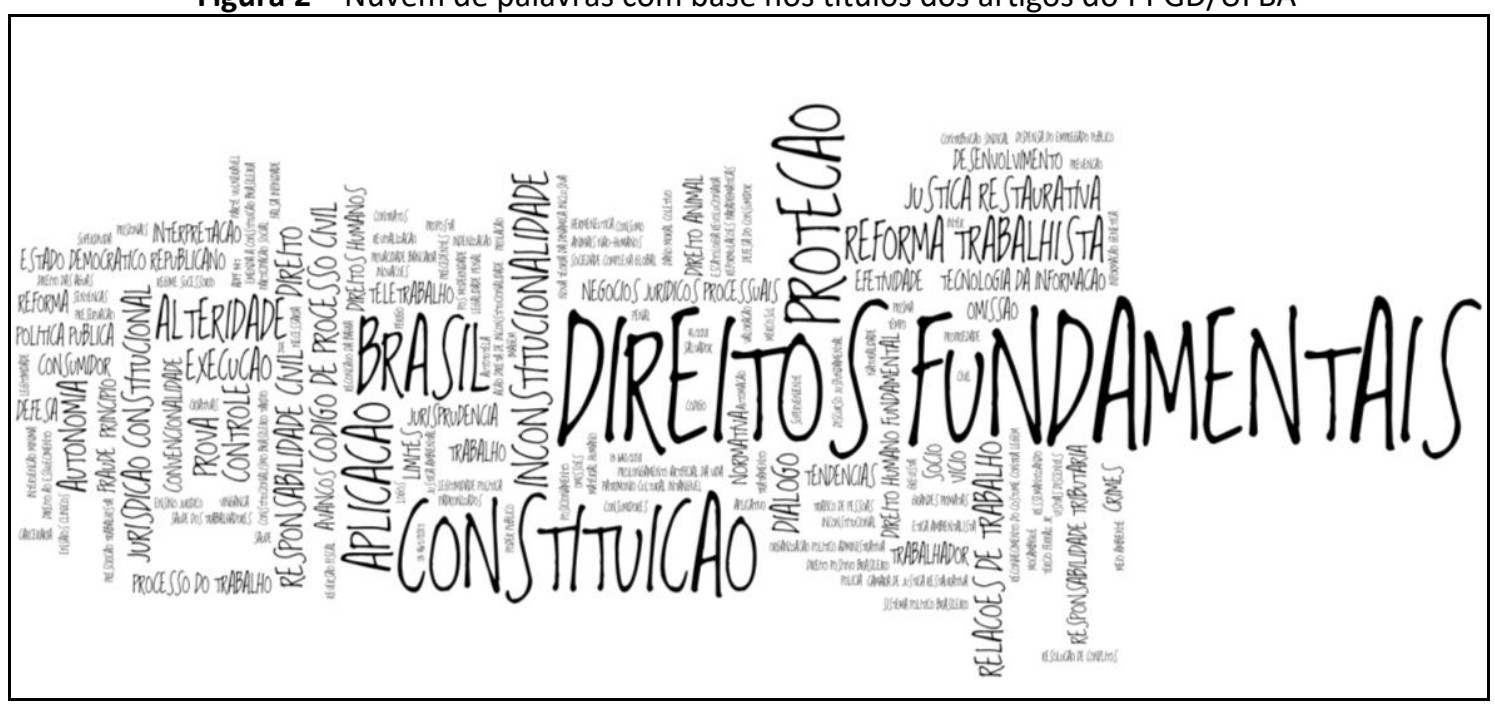

Fonte: Dados da pesquisa (2020)

Segundo Bonavides (1997), os direitos fundamentais são aqueles que receberam da Constituição um grau mais elevado de garantia ou de segurança. Segundo Silva (2006), são os direitos do homem jurídico-institucionalizadamente garantidos. Seriam os direitos objetivamente vigentes em uma ordem jurídica concreta, ou seja, são os enunciados constitucionais de cunho declaratório, cujo objetivo consistiria em reconhecer, no plano jurídico, a existência de uma prerrogativa fundamental do cidadão (SILVA, 2006).

Feita esta explanação, em seguida, buscou-se verificar as relações entre os autores, seus coautores e os ramos do Direito nas publicações de artigos em periódicos científicos. $\mathrm{Na}$ Figura 3, em verde, estão os pesquisadores do PPGD/UFBA; em vermelho, aparecem seus coautores; e os ramos do Direito estão postos em azul. O tamanho dos nós é proporcional à ocorrência de artigos científicos relacionados às variáveis representadas e a espessura das linhas reflete a intensidade das relações e vínculos entre os nós. O objetivo deste grafo é identificar as especialidades temáticas do grupo analisado. 
Figura 3 - Pesquisadores do PPGD/UFBA e seus coautores vs Ramos do Direito nas publicações de artigos

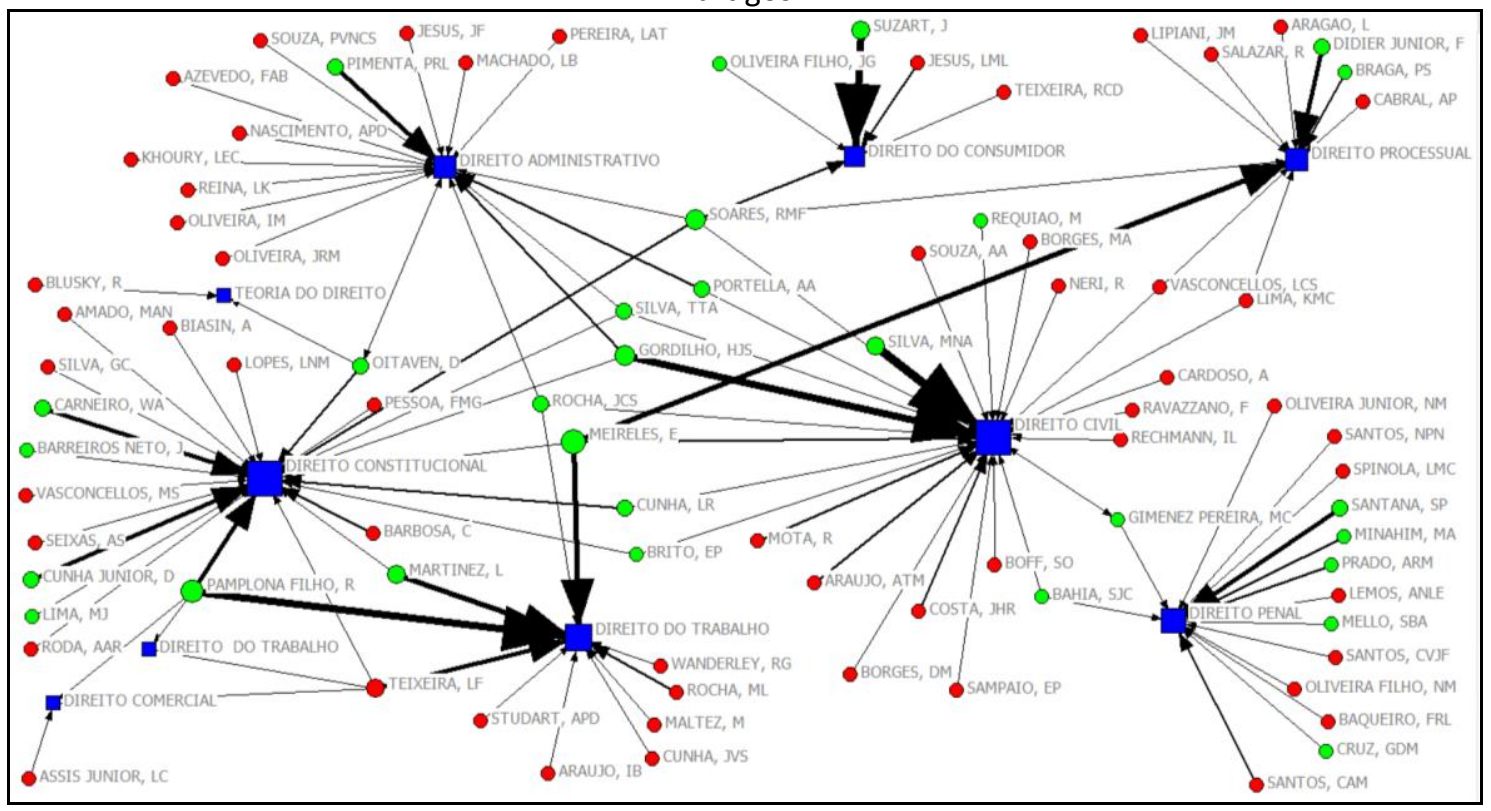

Fonte: Dados da pesquisa (2020)

As relações mais profícuas entre os pesquisadores e os ramos do Direito são: Silva, MNA \& Direito Civil (6); Gordilho, HJS, Suzart, J, Pamplona Filho, R \& Direito Civil (5); Martinez, L \& Direito do Trabalho (4); Meireles, E \& Direito Processual (4); Didier Junior, F \& Direito Processual (3); Teixeira, LF \& Direito do Trabalho (3); Pamplona Filho, R, Carneiro, WA, Cunha Junior, D \& Direito Constitucional (3); Pimenta, PRL \& Direito Administrativo (3); Santana, SP \& Direito Penal (3).

Observa-se que Silva, MNA \& Direito Civil são os que estão mais relacionados entre si. Esse resultado ocorre devido à Linha de Pesquisa adotada pela pesquisadora: Direitos PósModernos: Bioética, Cibernética, Ecologia e Direito Animal. Sua pesquisa concentra-se em questões de Biodireito, ramo que guarda estreitas relações com o Direito Civil.

Também associado a este enfoque, Gordilho, HJS traz em seus artigos discussões sobre o ramo do Direito Animal, enquanto Suzart, J e Pamplona Filho, $R$ atuam em Direitos Fundamentais, Cultura e Relações Sociais. Os artigos de Suzart, J versam sobre questões pertinentes ao Direito do Consumidor, ramo do Direito Civil, ao passo que o pesquisador Pamplona Filho, $R$ desenvolve pesquisa no campo do Direito do Trabalho, ramo historicamente relacionado ao Direito Civil.

\subsection{Publicações do PPGD/UFBA em periódicos e suas variáveis}

O Gráfico 2 projeta as revistas científicas mais proeminentes, no quesito publicações, no âmbito do PPGD/UFBA. Neste sentido, optou-se pela visualização em barras horizontais, pois expressam adequadamente o ranqueamento dos dados. Conforme afirma Barata (2015), os periódicos científicos interferem fortemente na produção científica dos países, sendo o carro-chefe da produtividade de acadêmicos. Estes veículos possuem grande importância para as Universidades e Programas de Pós-Graduação, servindo como um critério para análise da qualidade destas instituições (SIEBERT, 2019), seja através da avaliação da força de suas próprias revistas ou do impacto dos periódicos em que seus pesquisadores publicam. 
Gráfico 2 - Periódicos mais representativos nas publicações do PPGD/UFBA

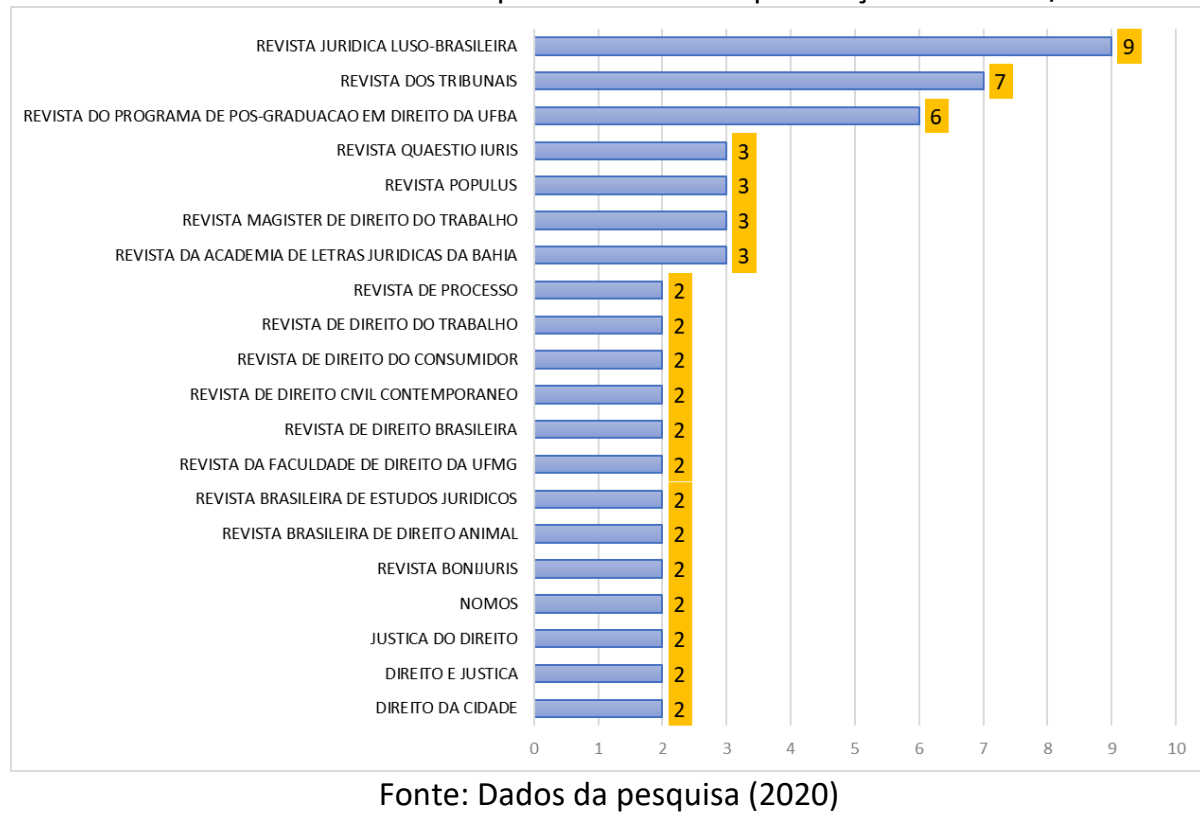

Os periódicos científicos que concentram a maioria dos artigos dos docentes do PPGD/UFBA são: Revista Jurídica Luso-Brasileira (RJLB), Revista dos Tribunais e Revista do Programa de Pós-Graduação em Direito da UFBA.

A RJLB, cuja primeira edição ocorreu em 2015, trata-se de uma publicação de âmbito internacional que visa promover a produção e a partilha científicas na área do Direito e em áreas afins e procura contribuir prioritariamente para a cultura jurídica de Portugal e do Brasil, facultando o acesso a trabalhos que possam ser entendidos como representativos da vanguarda científica em ambos os países (REVISTA JURÍDICA LUSO-BRASILEIRA, 2015).

A Revista dos Tribunais foi fundada, em 1912, pelo advogado e jornalista paulista Plínio Barreto, que ocupou o governo provisório de São Paulo durante a Revolução de 1930 (SILVEIRA, 2011). Desde então, teve publicação ininterrupta, mesmo em períodos de guerras e ditaduras. A cada volume, a Revista dos Tribunais aborda os temas do Direito de maneira multidisciplinar, selecionando jurisprudências que são comentadas por profissionais da área, contendo remissões para doutrinas que tratam do mesmo assunto, remissões para jurisprudências no mesmo sentido e no sentido oposto do julgado, ementas preparadas pela equipe - destacando os pontos mais importantes da decisão -, além de índice alfabéticoremissivo para facilitar a consulta (THOMSON REUTERS, 2020).

Complementa a terceira posição do ranking, a revista do próprio programa, denominada Revista do Programa de Pós-Graduação em Direito da UFBA, refletindo a existência de endogenia, porém, pouco representativa diante do espectro amplo de periódicos científicos exógenos em que as produções dos pesquisadores são escoadas.

O Qualis Capes é um sistema que faz a classificação da produção científica dos programas de pós-graduação brasileiros. No que concerne ao Qualis periódicos, é atribuído um estrato às revistas conforme a área do conhecimento em que estão classificadas, sendo possível a um periódico possuir várias estratificações, a depender da área do conhecimento. Existe uma categorização básica que varia de acordo com indicadores de qualidade, que vão de A1 - mais elevado -, passando por A2, B1, B2, B3, B4, B5, até C, com peso zero. Assim, apresenta-se no Gráfico 3, a estratificação de qualidade dos 99 artigos presentes no corpus deste estudo. 
Gráfico 3 - Classificação Qualis das publicações em periódicos do PPGD/UFBA na área de avaliação "Direito"

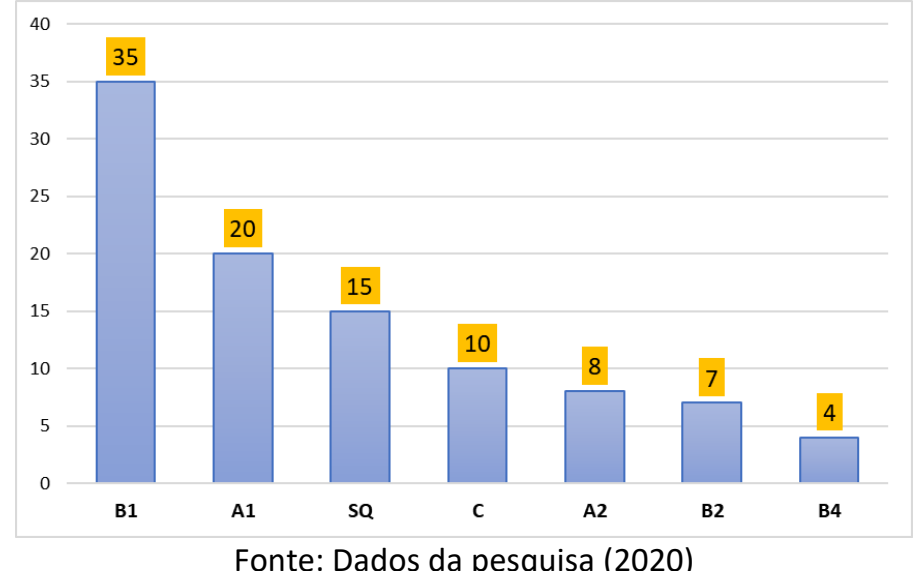

No Gráfico 3, se vê o destaque dos estratos: $B 1$ (35) e $A 1$ (20). Ademais, encontram-se: Sem Qualis (15), $C$ (10), A2 (8), B2 (7) e B4 (4). Com isto, conclui-se que 55,5\% das publicações do PPGD/UFBA, mais da metade, foram publicadas em periódicos classificados nos estratos $B 1$ e A1. Conforme indicado na metodologia, este estudo utiliza-se do Qualis vigente (2013-2016)

Os artigos em periódicos sem estrato apresentam-se em quantidade significativa e, provavelmente, contemplam papers publicados em periódicos novos ou que estão qualificados em outras áreas. Com isto, ressalta-se que os periódicos sem Qualis não necessariamente são revistas científicas de baixa qualidade. A ausência de estratificação pode também indicar um periódico em fase de consolidação ou, então, um veículo com estratificação em outros campos.

Assim, mesmo com o advento do novo Qualis unificado, ainda a ser instituído e tendente a ser mais rigoroso devido ao privilégio às publicações internacionalmente indexadas e possuidoras de fator de impacto, é possível que ocorra diminuição no quantitativo de periódicos sem Qualis em áreas específicas, pois, se o veículo possuir classificação em outra área, este estrato poderá ser generalizado para todas. Tudo dependerá da composição adotada por este novo sistema, que, antes mesmo de ser lançado, já é objeto de crítica e aclamação por correntes distintas da comunidade científica brasileira, gerando um profícuo debate em torno de seu aperfeiçoamento, e até mesmo, da possibilidade de sua extinção.

A oportunidade de reformulação do modelo de estratificação da qualidade no campo jurídico tem gerado muitas expectativas, sobretudo, pelas peculiaridades existentes no Direito. A avaliação da pesquisa nesta área é um tema delicado devido à heterogeneidade das pesquisas e dos produtos científicos, à especialidade dos canais de comunicação e à ausência de dados objetivos à avaliação, em razão da pouca cobertura de bancos de dados citacionais. Por isso, há uma a inaplicabilidade nesta área dos principais critérios de avaliação adotados no mundo das ciências exatas (CAPPARELLI; GIACOMOLLI, 2017). Em concordância, Varella e Roesler (2012) criticaram as metodologias de avaliação de publicações na área de Direito aplicadas nos últimos anos, afirmando que estas, dificilmente, podem ser consideradas adequadas, pois nada mais são do que importações de outras áreas do conhecimento.

No mais, reconhece-se que a área jurídica possui uma importante relação com o livro. Este dado histórico pode ser observado, por exemplo, em Silva (2013), quando aponta, com base em dados bibliométricos de um universo bem circunscrito da área de Direito, que $56,1 \%$ das citações eram destinadas a livros, enquanto, apenas 18,9\% a periódicos. A importância do livro no campo e seu protagonismo histórico faz com que os pesquisadores da área jurídica optem por esta tipologia, dadas as possibilidades de consagração que ela oferece. De todo 
modo, na coleta de dados realizada para o presente artigo sobre o PPGD/UFBA, notaram-se 99 artigos completos publicados em periódicos, 56 livros publicados/organizados e 112 capítulos de livros publicados, ou seja, o paradigma das publicações periódicas, fortemente presente no mercado editorial acadêmico, começou a diminuir o abismo entre as tipologias, equilibrando as relações com o livro.

Sobre isto, Silveira e Sanches (2016), ao discutirem o desafio da superação da cultura exclusiva do livro no Direito, afirmaram, que esta passa, pelo estímulo aos alunos na busca por artigos de periódicos como fonte bibliográfica na graduação. No mais, os autores reforçam o comprometimento dos periódicos com a qualidade do que é publicado, ressaltando sua facilidade de circulação rápida e democrática, principalmente, pelos meios eletrônicos (SILVEIRA; SANCHES, 2016). O livro, apesar de ser um instrumento fantástico de transformação social, digno de protagonismo em todas as esferas da sociedade, inclusive, na científica, ao longo dos anos, vem sendo usado no Direito como meio de sustentação de uma indústria editorial, contribuindo para que o curso de Direito mantenha-se dispendioso e elitizado, pois nem todos os alunos de graduação e pós-graduação possuem condições para aquisição deste recurso. Assim, o campo precisa ampliar a produção e disseminação de informação em veículos de livre acesso, sejam periódicos científicos ou livros inseridos nesta categoria.

Adiante, apresentam-se as relações entre o Qualis dos periódicos e os ramos do Direito, com o propósito de verificar as categorias que vêm obtendo melhor desempenho (Figura 4).

Figura 4 - Qualis Capes dos periódicos vs ramos do Direito nas publicações de artigos do PPGD/UFBA

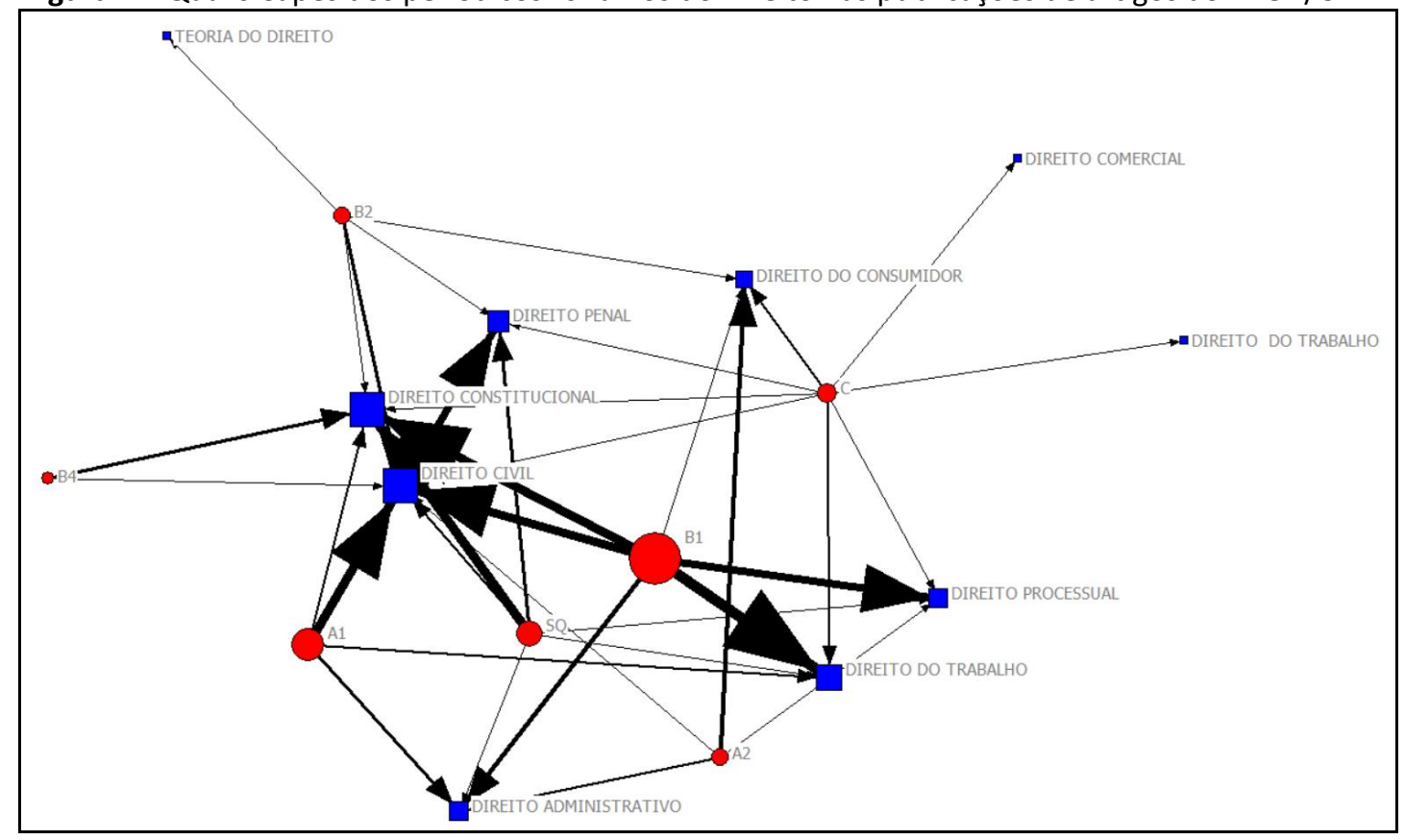

Fonte: Dados da pesquisa (2020)

Os periódicos classificados como A1 priorizam os ramos do Direito Civil (7), Penal (6) e Administrativo (3); aqueles classificados como A2 concentram-se em Direito do Consumidor (4) e Administrativo (2). Periódicos com Qualis B1 privilegiam os ramos do Direito do Trabalho (9), Constitucional (8), Civil (7) e Processual (6); converge para periódicos com Qualis B2, o ramo do Direito Civil (3); e para B4, o Direito Constitucional (3). Dentre os ramos presentes nos periódicos sem Qualis, sobressaem-se: Direito Constitucional (7), Penal (3) e Civil (2). 
Percebe-se, portanto, predomínio em periódicos de excelência classificados no Qualis A, os artigos com enfoque em Direito Civil, Penal, Administrativo e do Consumidor; enquanto, nos estratos inferiores e sem estrato, nota-se a frequência elevada de artigos sobre Direito Constitucional. De certo, não se pretende defender que o tema é uma variável determinística do Qualis de uma publicação, pois, deve-se considerar, primeiramente, a qualidade do artigo. Todavia, importa observar que os periódicos inseridos nos estratos mais elevados possuem um foco e escopo determinado, favorecendo, algumas pesquisas em detrimento de outras. Com isto, determinados temas e ramos do Direito tendem a obter melhor desempenho no alcance dos níveis mais elevados de estratificação.

\section{CONSIDERAÇÕES FINAIS}

Este artigo objetivou descrever os ramos de pesquisa e as redes de colaboração na produção científica do PPGD/UFBA, no ano 2018. Assim, percebeu-se: o destaque dos ramos do Direito Civil e Direito Constitucional e as colaborações científicas entre Teixeira, L.F. \& Pamplona Filho, $R$.

Notou-se, também, que as publicações do PPGD/UFBA se concentram, em sua maioria, em periódicos nacionais e internacionais, classificados em estratos de grande qualidade (B1 e A1). Viu-se a proeminência dos periódicos científicos RJLB, Revista dos Tribunais e Revista do Programa de Pós-Graduação em Direito da UFBA como veículos preferenciais para escoamento da produção do Programa.

Conforme sugerido por Moura e Silva (2015), há outras importantes agendas de pesquisa no âmbito bibliométrico no campo do Direito, envolvendo, estudos de teses e dissertações, instituições dos coautores e suas posições geográficas, entre outras variáveis. Desta feita, pretende-se congregar estas sugestões em estudos futuros, com o alvo de abranger espectros mais profundos do PPGD/UFBA. De todo modo, as variáveis aqui contempladas foram suficientes para o alcance dos objetivos.

Espera-se que esta pesquisa inspire novos estudos no campo do Direito, contribuindo para a avaliação da comunicação científica da área, principalmente, valendo-se dos recursos da ARS e dos Estudos Métricos da Informação (Bibliometria, Cientometria, Informetria e Altmetria). Este tipo de pesquisa possui vários impactos positivos, que vão desde o levantamento de indicadores para as avaliações das instâncias pertinentes à própria universidade, até a prestação de subsídios gerenciais às instâncias reguladoras e agências de fomento, repercutindo no desenvolvimento de políticas de pessoal para o aumento da interação entre os pesquisadores do grupo e programas para a melhoria da qualidade das pesquisas.

No mais, os resultados sistematizados contribuem para a prestação de contas à sociedade sobre o desenvolvimento de atividades científicas e acadêmicas realizadas no âmbito da Universidade Pública, ajudando a divulgar o papel da instituição como um espaço livre, criativo, produtivo, diversificado, transparente e intelectualmente ativo.

\section{REFERÊNCIAS}

ALBERGARIA, B. Instituições de direito: para cursos de administração, ciências contábeis, economia, comércio exterior e ciências sociais. São Paulo: Atlas, 2008. 463 p. 
AMARAL, F. Historicidade e racionalidade na construção do direito brasileiro. In: MARTINSCOSTA, J. (org.). A reconstrução do direito privado: reflexos dos princípios, diretrizes e direitos fundamentais constitucionais no direito privado. São Paulo: RT, 2002.

ANTONIO, I. Autoria e cultura na pós-modernidade. Ciência da Informação, Brasília, v. 27, n. 2, 1998. Disponível em: https://www.scielo.br/pdf/ci/v27n2/irati.. Acesso em: 01 mar. 2020.

BARATA, R. Periódicos científicos marcam autoria, difundem conhecimento e buscam reinvenção. Ciência e Cultura, São Paulo, v. 67, n.1, jan./mar. 2015. Disponível em: http://cienciaecultura.bvs.br/scielo.php?script=sci arttext\&pid=S0009-67252015000100006. Acesso em: 01 set. 2020.

BARDIN, L. Análise de conteúdo. Tradução de Luís A. Reto e Augusto Pinheiro. 5. ed. Lisboa: Edições 70, 2009.

BONAVIDES, P. Curso de direito constitucional. São Paulo, Malheiros, 1997.

BORGATTI, S. P.; EVERETT, M. G.; FREEMAN, L. C. UCINET for windows: software for social network analysis. Harvard: Analytic Technologies, 2002.

BRITTES, J. G.; PEREIRA, J. L. Tecnologias da informação e da comunicação e a polêmica sobre direito autoral: o caso Google Book Search. Ciência da Informação, Brasília, v. 36, n. 1, p. 167174, abr. 2007. Disponível em: http://www.scielo.br/scielo.php?script=sci arttext\&pid=S010019652007000100013\&lng=en\&nrm=iso. Acesso em: 01 mar. 2020.

CAPPARELLI, B.; GIACOMOLLI, N. J. A avaliação do Impact Factor na publicação científica de Direito Processual Penal. Revista Brasileira de Direito Processual Penal, v. 3, n. 3, p. 789-806, 2017. Disponível em: http://www.ibraspp.com.br/revista/index.php/RBDPP/article/view/108.. Acesso em: 01 mar. 2020.

CARLI, D. T.; FACHIN, G. R. B. A Lei de Acesso à Informação e a gestão de documentos. Biblios, Pittsburgh, n. 66, p. 47-59, jan. 2017. Disponível em: http://www.scielo.org.pe/scielo.php?script=sci arttext\&pid=S1562$\underline{47302017000100005 \& \operatorname{lng}=e s \& n r m=i s o}$. Acesso em: 01 mar. 2020.

CARLOMAGNO, M. C.; ROCHA, L. C. da. Como criar e classificar categorias para fazer análise de conteúdo: uma questão metodológica. Revista Eletrônica de Ciência Política, Curitiba, v. 7, n. 1, p. 173-188, jul. 2016. Disponível em: https://revistas.ufpr.br/politica/article/view/45771. Acesso em: 01 mar. 2020.

CARVALHO, D. Q. Classificação Decimal de Direito. 4. ed. Brasília: Presidência da República, 2002. Disponível em: http://www4.planalto.gov.br/centrodeestudos/assuntos/classificacaodecimal-de-direito/classif-decimal.pdf. Acesso em: 03 abr. 2020.

CARVALHO, M. Manual de Direito Administrativo. 6. ed. Salvador: Juspodivm, 2019.

FACHIN, L. E. Avaliação da pós-graduação em direito: reflexões sobre o perfil da excelência acadêmica. In: SILVEIRA, Vladmir Oliveira da; SANCHES, Samyra Haydêe dal Farra Naspolini; COUTO, Mônica Bonetti (org.). Educação Jurídica. São Paulo: Saraiva, 2013. p. 295-310. 
FERRAZ JÚNIOR, T. S. Introdução ao Estudo do Direito: técnica, decisão, dominação. 4. ed. São Paulo: Atlas, 2003.

FERREIRA, J. R. Apresentação. In: PINHEIRO, Lena Vania Ribeiro (org.). Ciência da Informação, Ciências Sociais e interdisciplinaridade. Brasília: Ibict, 1999. p. 7-7. Disponível em: https://livroaberto.ibict.br/bitstream/1/1000/1/PINHEIRO.\%20Ci\%c3\%aancia\%20da\%20Inform a \%c3\%a7\%c3\%a30,\%20Ci\%c3\%aancias\%20Sociais\%20e\%20Interdisciplinariedade.pdf. Acesso em: 01 jun. 2020.

FRAGALE FILHO, R.; VERONESE, A. A pesquisa em Direito: diagnóstico e perspectivas. Revista Brasileira de Pós-Graduação, v. 1, n. 2, 11. Disponível em: http://ojs.rbpg.capes.gov.br/index.php/rbpg/article/view/40. Acesso em: 03 abr. 2020.

FUIITA, M. S. L. A identificação de conceitos no processo de análise de assunto para indexação. Revista digital de biblioteconomia e ciência da informação, v. 1, n. 1, p. 60-90, jul/dez. 2003. Disponível em: http://eprints.rclis.org/6266/1/Fujita.pdf._Acesso em: 03 abr. 2020.

GIGANTE, J. A. M. Instituições de Direito Canônico, vol. III. 3. ed. Braga: Esc. Tip. da Oficina de S. José, 1954.

GTDJMG, Catálogo coletivo de periódicos em ciências jurídicas. Revista de Biblioteconomia de Brasília, v. 5, n. 2, 1977.

HEGEL, G. W. F. Princípios da filosofia do direito. 2. ed. São Paulo: Martins Fontes, 2003.

HJØRLAND, B. Domain analysis. In: HJØRLAND, Birger; GNOLI, Claudio (Ed.). Encyclopedia of Knowledge Organization. 1.3, [s.I.]: Isko, 2017. p. 1-2. Disponível em: https://www.isko.org/cyclo/domain analysis.htm. Acesso em: 15 set. 2020.

HJøRLAND, B. Domain analysis in information science: eleven approaches-traditional as well as innovative. Journal of documentation, v. 58, n. 4, p. 422-462. 2002.

KLAUSNER, E. A. Sobre o reconhecimento na República Federativa do Brasil de diploma de pósgraduação stricto sensu em direito canônico expedido por universidade da Santa Sé. Quaestio luris, Rio de Janeiro, v. 12, n. 2, p. 360-400, 2019.

KRIPPENDORFF, K. Content analysis: an introduction to its methodology. 2. ed. Thousand Oaks, Ca: Sage Publications, 2004.

MARTINS, R.; ALMEIDA, C. C. Direito e Ciência da Informação: uma possibilidade de interface disciplinar. Ibersid, v. 6, p. 145-152, ago. 2012. Disponível em:

http://hdl.handle.net/11449/114679. Acesso em: 02 out. 2019.

MARTINS FILHO, P. Direitos autorais na internet. Ciência da Informação, Brasília, v. 27, n. 2, p. 183-188, maio/ago. 1998. Disponível em: https://www.scielo.br/scielo.php?pid=S010019651998000200011\&script=sci arttext. Acesso em: 02 out. 2019.

MASCARO, A. L. Introdução ao estudo do direito. 5. ed. São Paulo: Atlas, 2015. 
MENA-CHALCO, J. P.; CESAR JUNIOR, R. M. ScriptLattes: an open-source knowledge extraction system from the Lattes platform. Journal of the Brazilian Computer Society, Campinas, v. 15, n. 4, p. 31-39, dez. 2009. Disponível em: http://www.scielo.br/pdf/jbcos/v15n4/04.pdf. Acesso em: 5 jun. 2020.

MICHEL, J. Direito de autor, direito de cópia e direito à informação: o ponto de vista e a ação das associações de profissionais da informação e da documentação. Ciência da Informação, Brasília, v. 26, n. 2, maio/ago. 1997. Disponível em:

https://www.scielo.br/scielo.php?script=sci arttext\&pid=S010019651997000200005\&lng=pt\&nrm=iso. Acesso em: 5 jun. 2020.

MOURA, W. J. F. de.; SILVA, J. S. F. da. Produção doutrinária em direito do consumidor: um estudo bibliométrico da Revista de Direito do Consumidor. Revista de Direito do Consumidor, São Paulo, v. 100, p. 43-57, jul.-ago. 2015

PEDRINI, I. A. D. A questão do aboutness em documentos narrativos ficcionais: subsídios para a análise documental de crônicas. 2007. 84 f. Dissertação (Mestrado em Ciência da Informação) - Universidade Estadual Paulista, Faculdade de Filosofia e Ciências, 2007.

REVISTA JURÍDICA LUSO-BRASILEIRA. CIDP: Revista Jurídica Luso-Brasileira (RJLB). Lisboa: Portugal, 2015. Disponível em: http://www.fd.ulisboa.pt/cidp-revista-juridica-luso-brasileirarilb-n-o1/. Acesso em: 01 mar. 2020.

SIEBERT, S. Produção e divulgação de periódicos científicos. Linguagem em (Dis)curso, Tubarão, v. 19, n. 3, p. 381-382, dez. 2019. Disponível em: http://www.scielo.br/scielo.php?script=sci arttext\&pid=S151876322019000300381\&lng=en\&nrm=iso. Acesso em: 01 mar. 2020.

SILVA, A. A. Vida média da literatura em Direito: um estudo bibliométrico aplicado a um periódico jurídico. 33f. 2013. Trabalho de conclusão de curso (Graduação) - Curso de Biblioteconomia e Gestão de Unidades de Informação, Universidade Federal do Rio de Janeiro. Rio de Janeiro, 2013. Disponível em:

https://pantheon.ufrj.br/bitstream/11422/195/1/ARIADNE.VIDAMEDIA.2013.pdf. Acesso em: 01 mar. 2020.

SILVA, A. K. A. A dinâmica das redes sociais e as redes de coautoria. Perspectivas em Gestão \& Conhecimento, v. 4, p. 27-47, 26 out. 2014. Disponível em: https://periodicos.ufpb.br/index.php/pgc/article/view/21275/11747. Acesso em: 01 mar. 2020.

SILVA, F. M. A. da. Direitos Fundamentais. In: Direitonet: portal eletrônico de informações, 2006. Disponível em: http://www.direitonet.com.br/artigos/exibir/2627/DireitosFundamentais. Acesso em: 01 mar. 2020.

SILVA, J. A.; BIANCHI, M. de. L. P. Cientometria: a métrica da ciência. Paidéia, Ribeirão Preto, v. 11, n. 21, p. 5-10, 2001. Disponível em: https://www.scielo.br/scielo.php?script=sci arttext\&pid=S0103-863X2001000200002. Acesso em: 01 mar. 2020.

SILVA, R. S. M. A ciência do Direito. Revista Jus Navigandi, Teresina, ano 11, n. 1256, 9 dez. 2006.

Perspectivas em Gestão \& Conhecimento, João Pessoa, v. 11, n. 1, p. 99-117, jan./abr. 2021. 
SILVEIRA, M. de. M. "Um processo de difusão e desenvolvimento cultural excelente": a revista Direito e os periódicos jurídicos no Brasil da passagem dos anos 1930 aos anos 1940. In: XXVI SIMPÓSIO NACIONAL DE HISTÓRIA, 2011, São Paulo. Anais.... São Paulo: ANPUH-SP, 2011. Disponível em:

http://www.snh2011.anpuh.org/resources/anais/14/1308166992 ARQUIVO TextoANPUH.pdf . Acesso em: 01 mar. 2020.

SILVEIRA, V. O.; SANCHES, S. H. F. N. Periódicos na área do Direito: o desafio da superação da cultura dos livros. RFD-Revista da Faculdade de Direito da UERJ, n. 30, p. 157-172, 2016. Disponível em: https://www.e-publicacoes.ueri.br/index.php/rfdueri/article/view/17961. Acesso em: 03 out. 2019.

SOBRIÑO, H. E. Notas para uma biblioteca de direito. Revista de Biblioteconomia de Brasília, Brasília, v. 7, n. 2, p. 250-255, jul./dez. 1979. Disponível em:

http://hdl.handle.net/20.500.11959/brapci/77661. Acesso em: 03 out. 2019.

TAGUE-SUTCLIFFE, J. An introduction to informetrics. Information Processing \& Management, v. 28, n. 1, p. 1-3, jan./feb. 1992.

THOMSON REUTERS. Revista dos Tribunais. 2020. Disponível em:

https://www.thomsonreuters.com.br/pt/juridico/webrevistas/RT-revistas-dos-tribunais.html. Acesso em: 01 mar. 2020.

VARELLA, M. D.; ROESLER, C. R. Dificuldades de avaliação de publicações na área de Direito. Revista Brasileira de Pós-Graduação, v. 9, n. 18, 2012. Disponível em: http://ojs.rbpg.capes.gov.br/index.php/rbpg/article/view/361. Acesso em: 01 mar. 2020. 


\section{Apêndice A - Código Lattes, Nome, Período e Categoria de Participação no PPGD/UFBA do Universo Selecionado}

2158993363327030, Alessandra Rapacci Mascarenhas Prado , 2018 , PERMANENTE 1782631349656661, André Alves Portella , 2018 , COLABORADOR 8781398044703228, Antônio Carlos Oliveira Gidi , 2018, COLABORADOR 6313557911258738, Celso Luiz Braga de Castro , 2018, COLABORADOR 6017800397546356 , Daniel Oitaven Pamponet Miguel , 2018 , PERMANENTE 2828640231760353, Dirley da Cunha Junior , 2018, PERMANENTE 6602550613140098 , Edilton Meireles de Oliveira Santos , 2018 , PERMANENTE 5449987493997379 , Edvaldo Pereira de Brito , 2018 , PERMANENTE 3306637869298105, Elmir Duclerc Ramalho Junior , 2018, PERMANENTE 3021268770189132 , Fredie Souza Didier Junior , 2018 , PERMANENTE 1169364668008174 , Gabriel Dias Marques da Cruz , 2018 , PERMANENTE 0551615886512142, Gamil Foppel El Hireche , 2018, PERMANENTE 9247033382457379, Heron José de Santana Gordilho , 2018 , PERMANENTE 7494006136812603 , Jaime Barreiros Neto , 2018 , PERMANENTE 2865196765668319 , João Glicério de Oliveira Filho , 2018 , COLABORADOR 0054419168094362 , José Aurivaldo Sacchetta Ramos Mendes , 2018 , COLABORADOR 2454558688755602 , Joseane Suzart Lopes da Silva , 2018 , PERMANENTE 7066612031979191 , Júlio Cesar de Sá da Rocha , 2018 , PERMANENTE 4682265624995156 , Leandro Reinaldo da Cunha , 2018 , PERMANENTE 8883729921865765 , Luciano Dorea Martinez Carreiro , 2018 , PERMANENTE 8448823919067092 , Manoel Jorge e Silva Neto , 2018 , PERMANENTE 3711110042226464 , Maria Auxiliadora Minahim , 2018 , PERMANENTE 7173920835311611 , Marília Muricy Machado Pinto , 2018 , COLABORADOR 2759364549381451, Mario Jorge Philocreon de Castro Lima , 2018, COLABORADOR 6905306640861147 , Marta Carolina Gimenez Pereira , 2018 , PERMANENTE 3223008453117955 , Maurício Requião de Sant'Ana , 2018 , PERMANENTE 7536438369531146, Mônica Neves Aguiar da Silva , 2018, PERMANENTE 5962425503452433, Nelson Cerqueira , 2018, COLABORADOR 7487330325068541 , Paula Sarno Braga , 2018 , PERMANENTE 8867369272580850 , Paulo Roberto Lyrio Pimenta , 2018 , PERMANENTE 7597880442041621, Ricardo Maurício Freire Soares , 2018 , PERMANENTE 6474247848853228, Rodolfo Mário Veiga Pamplona Filho , 2018 , PERMANENTE 4201864045105091, Roxana Cardoso Brasileiro Borges , 2018, PERMANENTE 7398414546353246 , Saulo José Casali Bahia , 2018 , PERMANENTE 2042697331981933, Sebastian Borges de Albuquerque Mello , 2018 , PERMANENTE 1410037874765018, Selma Pereira de Santana , 2018, PERMANENTE 4247501480576742, Tagore Trajano de Almeida Silva , 2018, COLABORADOR 0599561795054566, Walber Araújo Carneiro , 2018 , PERMANENTE 3786348239005934 , Wilson Alves de Souza, 2018 , PERMANENTE 